REVISTA

\title{
MARIELLE VIVE! - O GRAFFITI COMO GÊNERO TEXTUAL COM POTENCIAL CRÍTICO PARA O ENSINO DA LÍNGUA PORTUGUESA
}

\author{
MARIELLE VIVE! - GRAFFITI AS A TEXTUAL GENRE WITH CRITICAL \\ POTENTIAL FOR PORTUGUESE LANGUAGE EDUCATION
}

\author{
Leonardo Bis dos Santos ${ }^{1 *}$ \\ Priscila de Souza Chisté Leite ${ }^{2}$ \\ ${ }^{1}$ Instituto Federal do Espírito Santo. E-mail:leonardo.bis@ifes.edu.br. \\ ${ }^{2}$ Instituto Federal do Espírito Santo. E-mail:pchiste@ifes.edu.br. \\ * Autor para correspondência.
}

Artigo submetido em 26/09/2019, aceito em 23/10/2019 e publicado em 20/12/2019.

Resumo: O objetivo deste estudo é apresentar o grafitti (arte urbana) como uma possibilidade de trabalho com gêneros textuais no ensino da língua portuguesa. Partimos da hipótese de que cabe a escola estimular o contato e a interpretação de textos que extrapolem abordagens tradicionais, muitas vezes recorrentes no contexto escolar. Como modo de exemplificar a proposta, discorremos um grafitti a partir dos princípios constitutivos da textualidade, apontados por Robert-Alain de Beaugrande e Wolfgang Dressler, em especial, os princípios da coesão, da intencionalidade, da situacionalidade e da intertextualidade e por metodologia de estudo de imagem, dando ênfase aos aspectos formais, contextuais, intertextuais e de conteúdo da obra em estudo. O texto verbo-visual apresentado foi registrado na Avenida Paulista, na cidade de São Paulo e remete ao assassinato da vereadora Marielle Franco. Por meio desse texto, com base nos pressupostos teóricos acima mencionados, constatamos que tais princípios constitutivos da textualidade, acrescidos de instrumental de análise imagética, contribuem para a compreensão de textos diferentes dos escritos, e podem servir de norteadores para a realização de relatos que visem compreender o texto para além de sua forma e da mera decodificação. Consideramos que cabe ao ensino da língua portuguesa, por meio de professores atentos, estimular os discentes a alçarem a condição de leitores críticos e responsivos, capazes de promoverem a discussão e o entendimento da realidade, visando à divulgação e potência das lutas sociais em defesa dos grupos marginalizados.

Palavras-chave: Marielle Franco; grafitti; gêneros textuais; ensino da língua portuguesa.

Abstract: The aim of this study is to present graffiti (urban art) as a possibility of working with textual genres in the teaching of the Portuguese language. We start from the hypothesis that it is up to the school to stimulate contact and analysis of texts that outnumber traditional approaches, often recurrent in the school context. As a way of exemplifying the proposal, we discuss a graffiti based on the constitutive principles of textuality, pointed out by Robert-Alain de Beaugrande and Wolfgang Dressler, in particular the principles of cohesion, intentionality, situationality and intertextuality and imaging methodology, emphasizing the formal, contextual, intertextual and content aspects of the work under study. The word-visual text presented was recorded on Avenida Paulista, in the city of São Paulo and refers to the murder of Councilwoman Marielle Franco. Through this text, based on the theoretical assumptions mentioned above, we found that such principles constituting textuality, plus 
instruments of imaging analysis, contribute to the understanding of texts different from writings, and can serve as guideers for making reports aimed at understanding the text beyond its form and mere decoding. We consider that it is up to the teaching of the Portuguese language, through attentive teachers, to encourage students to raise the condition of critical and responsive readers, capable of promoting discussion and understanding of reality, aiming at dissemination and power social struggles in defense of marginalized groups.

Keywords: Marielle Franco; grafitti; textual genres; Portuguese language teaching.

\section{INTRODUÇÃO}

$\mathrm{Na}$ atualidade, somos diariamente bombardeados por imagens que visam, de certo modo, nos convencer a comprar produtos ou modelar nosso comportamento. Inúmeros outdoors e outros textos ocupam as ruas e avenidas das cidades. São textos verbo-visuais divulgados por empresas que pagam por um espaço/tempo de propaganda. Outros textos espalhados pela cidade são mais despretensiosos, críticos e não institucionalizados, como o grafitti, por exemplo. Um olhar atento e questionador precisa ser estimulado para melhor compreensão da realidade em que vivemos. Consideramos que essa educação crítica possa ser promovida pela escola. Um dos espaços de discussão pode ser a aulas de Língua Portuguesa. Contudo, ainda percebemos que essas aulas são marcadas por práticas tradicionais, voltadas para 0 ensino da língua com foco na gramática e no ensino da norma culta.

Vários autores nos aguçam a modificar e problematizar essa visão tradicional. Eles propõem o estudo em sala de aula de diferentes gêneros textuais. Geraldi (2006) critica a abordagem pedagógica tradicional e argumenta que ela contribui com o fracasso escolar, pois limita o estudo da língua ao estudo da gramática, reduzindo-o a uma atividade mecânica e acrítica. Ele alerta que, em meio a discussões de como, quando e o que ensinar, esquecese de questionar o objetivo do ensino, ou seja, para que ensinar. Esse objetivo está diretamente ligado à concepção que o professor tem de linguagem e à sua postura com relação à educação. Nesse sentido, o autor defende a linguagem como forma de interação. Geraldi (2006) reforça a necessidade de formação do leitor crítico a partir da concepção de linguagem bakhtiniana, entendida como processo de interação verbal, considerando o leitor um sujeito ativo que se constitui de forma dialógica. Nesse contexto, a leitura é compreendida como prática social, auxiliando a pensar a realidade e desenvolver o senso crítico do leitor, ampliando sua participação social.

Entendemos que a Linguagem (com letra maiúscula pela sua importância) precisa ser apresentada na escola como um modo de interação. Nesse sentido, os sujeitos envolvidos em contextos enunciativos são agentes sociais que por meio do diálogo trocam experiências e conhecimentos.

Corroborando o pensamento tanto Geraldi quanto Buzen (2006) inferem que as aulas de produção de texto necessitam estar vinculadas a atividades de leitura que enfatizem a compreensão ativa e responsiva de diferentes gêneros textuais. A responsibilidade é um neologismo criado por Bakhtin (2010) que une responsabilidade (responder pelos próprios atos), à responsividade (responder a alguém ou a alguma coisa). É um responder responsável que envolve necessariamente um compromisso ético do agente (BAKHTIN, 2010). Tal compromisso pressupõe, entre outras coisas, conhecer o universo de gêneros textuais. Pressupõe leitura, mas também comprometimento ético com aquilo que é lido e também escrito. Essa responsibilidade é primeiramente do professor. A cada intervenção educativa a responsabilidade é dividida a tal ponto que jamais será aceito, nem pelo aluno nem pelo professor, 
vivenciar experiências que não promovam a criação e a crítica.

Ambos autores afirmam que, no contato com o interlocutor, o texto adquire outro significado, pois muda o contexto e muda também a consciência do leitor. $\mathrm{O}$ discurso proferido deixa de pertencer ao locutor e passa a ser compreendido por meio dos sentidos e da consciência do interlocutor. Desse modo, o leitor constituise, ao longo das diferentes experiências estéticas-literárias, por discursos e diferentes vozes.

Concordamos com Bakthin (1997) quando ele diz que a compreensão é sempre dialógica; os sentidos são constituídos na troca, no diálogo entre duas consciências. "Em toda parte temos o texto virtual ou real e a compreensão que ele requer. $\mathrm{O}$ estudo torna-se interrogação e troca, ou seja, diálogo" (BAKHTIN, 1997, p. 341).

Desse modo, inferimos que para formar leitores ativos, que assumam essa postura dialógica com o texto, o professor precisa compreender essa relação de dialogismo e levar em consideração que o entendimento de determinado texto para o aluno não será necessariamente igual à sua, pois está diretamente ligado ao contexto em que o aluno se insere, às suas vivências, às suas leituras e ao seu conhecimento de mundo, que não é igual ao de ninguém.

Conforme Orlandi (2012) existem leituras previstas para um texto, mas há sempre novas possibilidades de leitura, que vão variar de acordo com o contexto sóciohistórico do leitor. Assim, cabe ao professor mediar o processo de construção da história de leituras do aluno, estabelecendo desafios para a compreensão sem deixar de fornecer condições para que o discente seja capaz de assumir esses desafios.

A partir do que foi dito, compreendemos que existe a necessidade de repensar as práticas pedagógicas vinculadas ao ensino da Língua Portuguesa. Acreditamos que um dos caminhos possíveis seria apresentar textos promovedores de discussões que provocassem os alunos a repensar seu cotidiano e a sociedade como um todo. Reconhecemos que o trabalho o gênero grafitti poderia integrar esse campo de possibilidades. Contudo, cabe pensar em modos de analisar esse gênero. Um das alternativas seria por meio dos princípios da textualidade e seus vínculos com leituras de imagem que abarquem aspectos formais, contextuais, intertextuais e conteudísticos referentes à obra de arte.

\section{O GRAFITTI COMO LINGUAGEM URBANA: PRINCÍPIOS CONSTITUTIVOS TEXTUALIDADE \\ DA}

A dicotomia rural/urbano é cada vez menos sentida em vários aspectos da vida social, dada a intensidade dos meios de comunicação, entre outras mediações, que atravessam ambos espaços. Tal fenômeno promove, em grande medida e de modo geral, uma homogeneização das experiências. Contudo, alguns eventos sociais ainda são marcadamente associados ao modo de vida urbano, dadas as circunstâncias de ocorrência. Entre tais singularidades encontram-se os grafittis, que consideramos arte integrante da linguagem urbana.

Vale ressaltar que a utilização de imagens no meio urbano para comunicar algo, com uma intencionalidade específica, é bastante rotineiro: outdoors, placas comerciais e panfletos, são alguns exemplos. O grafitti, nesse contexto, possui elementos singulares em termos de linguagem, pois ocupa um lugar bastante específico no processo de linguagens.

A imagem do grafitti não tem como objetivo oferecer ou vender um produto exposto na grande vitrine que é a cidade. Essa peculiaridade é por si uma característica elementar para estudá-lo. Diferentemente de um outdoor, que vai utilizar um espaço da cidade para apresentar uma mensagem, na maioria das vezes carregada de imagens, o grafitti busca exprimir um componente de resistência 
social frente à própria urbanização ou denúncia a respeito de populações invisibilizadas e marginalizadas.

Nesse sentido, consideramos os grafittis presentes nos espaços urbanos como textos que expressam um conteúdo por meio de formas visuais. É possível presumir que para analisá-los podemos recorrer aos princípios da textualidade apontados por Robert-Alain de Beaugrande e Wolfgang Dressler no livro "Introduction to text linguistics", publicado em 1981. Textualidade, portanto, refere-se ao conjunto de características do texto, em uma dada situação de interação, que o fazem ser compreendido pelos leitores como um todo de sentido (BEAUGRANDE; DRESSLER, 1997). Segundo esses autores, o texto pode ser definido como uma ocorrência comunicativa que reúne sete princípios constitutivos da textualidade: coesão; coerência; intencionalidade; aceitabilidade; informatividade; situacionalidade e intertextualidade.

Consideramos também que os graffitis integram um conjunto de textos visuais ou verbo-visuais (caso sejam compostos por imagens e palavras), produções carregadas de sentidos que, para serem compreendidas, necessitam da interação da obra com sujeitos leitores responsivos, conforme apontamos na introdução deste artigo.

Além disso, inferimos que a leitura do grafitti extrapola a constatação de elementos dados apenas pela aparência/forma do texto, mas pressupõem também a análise de aspectos contextuais, intencionais e subjetivos (CHISTÉ, 2013). Ou seja, a compreensão do grafitti implica, entre outros fatores, o entendimento da situação na qual o texto foi criado. A própria ação de inscrição da mensagem no meio urbano, já que a própria atividade é marginalizada (não só socialmente, mas também legalmente na maior parte dos casos), carece de reflexão.

A análise deverá levar em consideração os modos de circulação da informação na cidade - e nesse ponto há convergência com os outdoors, uma vez que, do mesmo modo que o artista urbano, o anunciante vai desejar o local mais visível para exibição da sua mensagem. Contudo, no caso do grafitti, o momento de inscrição da mensagem deve levar em consideração, muitas vezes, a velocidade frente à possível chegada de repressores do ato. Assim, de uma maneira singular, o próprio local de inscrição é componente da leitura da informação. Fazer a leitura de um grafitti, linguagem muitas vezes marginal, transgressora e não legalizada, deverá ter em vista essas nuances.

Desse modo, na próxima seção analisaremos o grafitti "Marille Vive!" presente na cidade de São Paulo, por meio dos princípios constitutivos da textualidade, em especial, os princípios da coesão, intencionalidade, situacionalidade e intertextualidade; bem como por meio de leitura de imagem a partir dos pressupostos explicitados nesta seção.

\section{MARIELLE VIVE!}

Para apresentação do grafitti em questão, explicitaremos alguns princípios constitutivos da textualidade. Elencamos tais princípios, pois consideramos que eles nos ajudam a realizar uma leitura que pode promover uma compreensão mais aprofundada desse gênero de texto. $\mathrm{O}$ primeiro princípio que entendemos ser importante é o princípio da coesão, que diz respeito à forma como os elementos constituintes do texto conectam-se em uma sequência veiculadora de sentidos. $\mathrm{O}$ princípio da intencionalidade refere-se à atitude do produtor, relacionando-se com os propósitos do autor que podem ser: informar, convencer, relembrar, impactar etc. A situacionalidade diz respeito aos fatores que tornam o texto relevante para uma dada situação de ocorrência, aspectos que colaboram para a atribuição de sentidos e a compreensão do texto. Já a intertextualidade refere-se aos fatores que fazem a compreensão do texto depender do 
entendimento de textos que já existem (BEAUGRANDE; DRESSLER, 1997).

De modo geral, é possível presumir que, para a compreensão do grafitti, é necessário entender como os elementos formais, como as linhas, as texturas, a técnica utilizada pelo artista, se articulam com o conteúdo veiculado pela obra. A forma do graffiti relaciona-se de modo indissociável com o conteúdo divulgado pela obra. Tal conteúdo diz respeito à atitude do artista, suas intenções ao compor determinado trabalho. Os grafittis presentes no espaço urbano, respondem a algum acontecimento importante para um coletivo em especial ou a um chamado crítico que a própria cidade demanda. Os discursos veiculados pelo grafitti pressupõem também o diálogo com outros grafittis, com outros textos, sejam eles oriundos de fatos hodiernos ou provenientes da subjetividade e reflexões de outros artistas.

Tendo em vista que tais princípios se articulam, são fluidos e se misturam, passemos à análise do texto verbo-visual escolhido, a partir dos princípios constitutivos da textualidade elencados e da proposta de leitura de imagem explicitada.

Em meio ao caos na segurança pública pelo qual passa a região metropolitana do Rio de Janeiro, no dia 14 de março de 2018, a vereadora Marielle Franco foi assassinada juntamente com seu assessor Anderson Pedro Gomes. Marielle era militante das causas das periferias e, antes de ser vereadora, tinha assessorado o então deputado estadual Marcelo Freixo na comissão que investigou a atuação de milícias nas periferias do Rio de Janeiro. Apesar de ainda inconclusa, as investigações culminaram com a prisão do sargento reformado da Polícia Militar Ronnie Lessa, de 48 anos, e do ex-PM Elcio Vieira de Queiroz, de 46 anos, no dia 12 de março de 2019 - dois dias antes de completar um ano dos assassinatos.

Desde as primeiras informações divulgadas estimava-se que havia a participação de pessoal treinado com armas especiais das forças de segurança que atuam no estado - os laudos confirmavam a utilização de uma submetralhadora HK MP5, legalmente empregada apenas nas forças das polícias civil, militar e federal, instituições que por princípio deveriam zelar pela segurança da sociedade.

Com o início das investigações foram levantadas fortes suspeitas de que haveria interferências internas na própria polícia que dificultavam ou mesmo impediam a solução do crime. Todo o contexto que envolve o crime, a atuação política de Marielle Franco, a situação da segurança pública do estado do Rio de Janeiro, comprometida pela atuação das milícias, bem como as prisões efetuadas, deslocaram a pergunta mobilizadora inicial acerca do crime: ao invés de "quem matou", agora se pergunta "quem mandou matar Marielle Franco"?

Dada a ação política da vereadora assassinada, imediatamente, após a confirmação de sua violenta morte, milhares de manifestantes foram às ruas da cidade do Rio de Janeiro. O assassinato de Marielle e Anderson se transformou em uma grande mobilização em torno dos debates acerca dos direitos humanos e populações marginalizadas - negros, Lésbicas, Gays, Bissexuais, Travestis, Transexuais e Transgêneros (LGBTQ+), mulheres, favelados etc. Logo essa mobilização extrapolou os limites da região metropolitana do Rio de Janeiro, alcançando ruas e praças das principais cidades brasileiras, bem como manifestações ao redor do mundo - Alemanha, Bélgica e França, só para citar as algumas que foram publicadas pela imprensa.

Emerge desse contexto um grito de ordem que representa a luta da vereadora assassinada, de modo a não deixar que esvaziem seu conteúdo de luta. "Marielle presente!" se transformou em sinônimo de pressão pela resolução do caso de seu assassinato, mas também de denúncia a toda ordem de opressão às minorias principalmente àquelas que Marielle mais estava conectada. 
Assim surgem várias manifestações sociais, além das mobilizações já citadas, em torno do que passou a representar Marielle para o país. Infelizmente a potência de seu discurso se baseou em sua própria morte, contudo, tem sido perenizado de várias maneiras.

Figuras 1 e 2: Grafitti na Avenida Paulista/ SP (registrado em 26 de março de 2018)
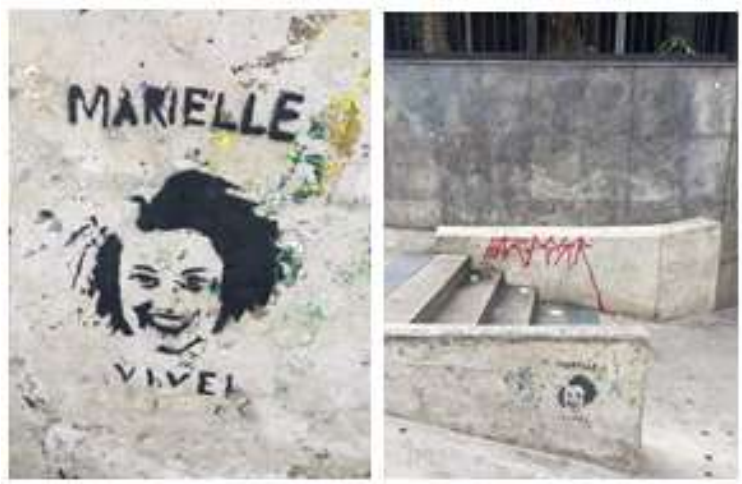

Fonte: Acervo pessoal

É possível considerar que o grafitti que estamos analisando (Figuras 1 e 2 ) integra tais manifestações. Discorrermos sobre esse texto, captado em 26 de março de 2018 - 12 dias após o assassinato -, revela que a cidade responde rápido aos acontecimentos que suscitam discussão, descontentamento e crítica. Cabe apontar que a contextualização do caso, conforme evidenciamos acima, refere-se predominantemente, ao princípio da situacionalidade.

A técnica utilizada para a criação dessa imagem foi o molde vazado, chamado também de máscara. Para compor a imagem, o artista aplicou somente a cor preta, aproveitando a cor do suporte utilizado para apresentação da obra, que, nesse caso, é a própria cidade cinza. A obra pode ser dividida em quatro partes: a escrita do nome Marielle; a imagem da vereadora; escrita do verbo conjugado no presente "Vive" (inferindo que mesmo após o assassinato as ideias de Marielle permanecem); e o ponto de exclamação que revela a indignação com ocorrido e a ênfase na permanência dos ideais militantes da vereadora. Tais elementos ao serem analisados relacionam-se ao princípio, predominantemente, de coesão.

Os elementos transgressores $\mathrm{e}$ denunciativos do grafitti estão nitidamente presentes, bem como o conteúdo sóciopolítico em torno da imagem de Marielle. O grito "Marielle presente" ficou conhecido e foi divulgado em todo Brasil e grande parte do mundo. Atualmente uma rua na cidade de Colônia, na Alemanha, e um espaço público em Paris, na França, recebem o nome de Marielle Franco, em homenagem à vereadora. Desse modo, a significação e ressignificação do graffiti está em constante transformação - no caso em tela, ganhando potência e conectando lugares geograficamente distantes.

$\mathrm{O}$ artista anônino apresenta neste graffiti um novo grito: "Marielle vive!" que de modo intertextual se relaciona analogamente ao grito de ordem "Marielle presente!", representando os ideais de uma militante que perdeu sua vida lutando. A imagem expressa resistência, frente ao cinza da cidade opressora, é icônica da luta experienciada em vida por Marielle.

Essa rede de textos organizados a partir deste assassinato compõe o princípio da intertextualidade, pois vários textos foram criados a partir desse crime, formando uma cadeia internacional de protestos e solicitações, expressados por diferentes textos como artigos de jornais, petições ao ministério público, grafittis, canções e poemas. Além disso, o grafitti criando pelo artista anônimo é marcado pelo princípio da intencionalidade, é uma marca, uma cicatriz deixada na cidade para que não nos esqueçamos do ocorrido e reivindiquemos por respostas.

\section{CONCLUSÕES}

Neste artigo buscamos apresentar novas possibilidades de trabalho com gêneros textuais, considerando que cabe à escola estimular o contato e a análise de textos que extrapolem abordagens tradicionais, muitas vezes recorrentes no 
contexto escolar. Por meio dos princípios constitutivos da textualidade, em especial, os princípios da coesão, intencionalidade, situacionalidade e intertextualidade; e de análise de imagem buscamos compreender um grafitti apresentado na Avenida Paulista, na cidade de São Paulo. Este texto verbovisual remete ao assassinato da vereadora Marielle Franco, e apresenta um novo grito de luta (Marielle Vive!) que estabelece relação intertextual com a frase de ordem que foi amplamente veiculada (Marielle Presente!).

Constatamos que tais princípios constitutivos da textualidade contribuem para a compreensão de textos diferentes dos escritos, e podem servir de norteadores para a realização de estudos que visem compreender o texto para além de sua forma e da mera decodificação. Consideramos que cabe ao ensino da língua portuguesa, por meio de professores atentos, estimular os discentes a alçarem a condição de leitores críticos e responsivos, capazes de realizar reflexões que promovam a discussão e o entendimento da sociedade, visando ao fortalecimento do pensamento coletivo, à divulgação e potência das lutas sociais em defesa dos grupos marginalizados e à necessidade constante de buscarmos a transformação desse modelo de sociedade.

\section{REFERÊNCIAS}

BAKHTIN, M. Para uma filosofia do ato responsável. São Carlos: Pedro \& João Editores, 2010.

BAKHTIN, Mikhail. Estética da criação verbal. Trad. Maria Ermantina Galvão G. Pereira. 2.ed. São Paulo: Martins Fontes, 1997.

BEAUGRANDE, R. de; DRESSLER, W. U. Introducción a la lingüística del texto. Barcelona: Ariel, 1997.

BUNZEN, Clécio. Da era da composição à era dos gêneros: o ensino de produção de texto no ensino médio. Português no ensino médio e formação do professor. São Paulo: Parábola Editorial, 139-161.

CHISTÉ, Priscila de Souza. Educação estética na educação profissional: mediações das obras de arte de Raphael Samú. 2013. Tese (Doutorado em Educação) - Universidade Federal do Espírito Santo, Vitória, 2013.

GERALDI, João Wanderley. Concepções de linguagem e ensino de português. In: GERALDI, João Wanderlei; ALMEIDA, Milton José de [et. al.] (Org.). O texto na sala de aula. São Paulo, Ática, 2006. p. 3946.

ORLANDI, Eni Pulcinelli. Discurso e leitura. 9. Ed. São Paulo: Cortez, 2012. 